\title{
A Decrease in the Amount and Function of the Stimulatory GTP-Binding Protein in the Small Resistance Arteries of Spontaneously Hypertensive Rats
}

\author{
Eishin SHIMIZU, Mitsumasa OHYANAGI, Motomaru MASUTANI, and Tadaaki IWASAKI
}

\begin{abstract}
We investigated the concentration of stimulatory GTP-binding protein (Gs protein) in the peripheral resistance arteries of spontaneously hypertensive rats (SHR), normotensive Wistar-Kyoto rats (WKY), and renovascular hypertensive rats (RHR). Changes in the function of Gs protein in SHR and WKY were also investigated by microcannulation techniques. The localization and abundance of Gs protein were determined immunohistochemically in 4-, 10- and 20-week-old SHR and age-matched WKY (control), as well as in RHR. Sections of the cremaster artery were stained with polyclonal antibodies to Gs protein. The concentration of Gs protein-like immunoreactivity in the cremaster artery was significantly lower in SHR at 4, 10, and 20 weeks of age, relative to that in age-matched WKY. In contrast, no significant differences were detected in the abundance of Gs between RHR and control rats. The dilatory response by isoproterenol in the presence of $\beta_{1}$ adrenoceptor blocker was lower in 4- and 10-week-old SHR than in age-matched WKY. The dilatory response by cholera toxin was also lower in SHR than in WKY for these two age groups. These results indicated that the amount and function of Gs protein in the peripheral resistance vessels in SHR was reduced. Since this change occurred before the onset of hypertension and no changes were seen in the secondary hypertensive rats, this change was not a secondary change due to hypertension. The impaired receptor-Gs protein-mediated signal transduction in the peripheral resistance arteries may be one of the possible mechanisms responsible for the pathogenesis of hypertension in SHR. (Hypertens Res 2002; 25: 743-749)
\end{abstract}

Key Words: Gs protein, immunohistochemistry, spontaneously hypertensive rats

\section{Introduction}

The peripheral resistance ateries are one of the main factors affecting blood pressure regulation. The contraction and dilator response of the resistance blood ateries through autonomous nerve play an important role in the control of systemic vascular resistance. The $\beta_{2}$-adrenergic receptor-stimulatory GTP-binding protein (Gs protein) in arterial smooth muscle cells plays a role in regulating the vascular dilation. The inhibitory GTP-binding protein (Gi protein) conducts stimuli to the $\alpha_{2}$-adrenoceptor and the $\mathrm{M}_{2}$-muscarinic receptors and plays an important role in regulation of vascular tone and vasoconstriction (1). Although the localization and function of $\mathrm{G}$ proteins have been examined in large blood vessels and cultured vascular smooth muscle cells $(2,3)$, there have been very few studies of the $G$ proteins in resistance arteries and their possible role in the pathogenesis and maintenance of hypertension (4). Moreover, the results that have been published often seem contradictory; for example, some studies have reported observing no changes in the levels of Gs protein in the aorta of hypertensive rats $(5-8)$, while others have shown a reduction in Gs protein in aortic smooth muscles $(9-11)$. We previously reported on changes in the level of Gi protein in small resistance arteries in spontaneously hypertensive rats (SHR) (4).

To clarify whether Gs protein plays a role in the development and maintenance of hypertension, we here investigated

From the Department of Internal Medicine, Cardiovascular Division, Hyogo College of Medicine, Nishinomiya, Japan.

Address for Reprints: Mitsumasa Ohyanagi, M.D., Department of Internal Medicine, Cardiovascular Division, Hyogo College of Medicine, 1-1, Mukogawa-cho, Nishinomiya 663-8501, Japan. E-mail: ohyanagi@hyo-med.ac.jp

Received February 25, 2002; Accepted in revised form April 30, 2002. 
the localization and concentration of Gs protein in the peripheral resistance arteries in SHR and normotensive WistarKyoto rats (WKY) using immunohistochemical methods. Changes in Gs function in the peripheral resistance arteries in SHR and WKY were also investigated. Moreover, to clarify whether the changes in Gs protein in SHR were congenital or secondary, we compared the concentration of Gs protein between SHR and rats with secondary hypertension.

\section{Methods}

SHR (aged 4, 10, and 20 weeks; each group, $n=7$ ) and agematched WKY (each group, $n=7$ ) were the descendants of animals provided by Kouzo Okamoto (Kinki Univ., Osaka-Sayama, Japan). As a secondary hypertensive animal model, renovascular hypertensive rats (RHR) were established by removing the right kidney from 7-week-old WKY and constricting the left renal artery with a silver clip $(n=5)$ (12); an increased systolic blood pressure over $180 \mathrm{mmHg}$ was confirmed 3 weeks after surgery. All animals received humane care and were maintained in accordance with the rules for animal experimentation of Hyogo College of Medicine. The systolic blood pressure of rats was measured by the tail-cuff method using an electro-sphygmomanometer (PE300; Tokai Irika, Oguchi-cho, Japan). Animals were anesthetized with diethyl ether and then perfused with Zamboni solution containing $2 \%$ paraformaldehyde, $0.2 \%$ picric acid, and $0.1 \mathrm{~mol} / \mathrm{l}$ sodium phosphate $(\mathrm{pH} 7.5)$. Subsequent procedures were performed at $4^{\circ} \mathrm{C}$ unless otherwise indicated. The abdominal aorta and the cremaster artery were removed, immersed overnight in the same fixative, incubated in a series of solutions of increasing sucrose concentration $[10,15,20$, and $25 \%(\mathrm{w} / \mathrm{v})]$, mounted in OCT embedding medium (MILES, Kankakee, USA), rapidly frozen, and finally sectioned with a cryostat. The $10 \mu \mathrm{m}$-thick frozen sections were mounted on APS-coated glass slides (Matsunami, Tokyo, Japan) and washed three times with $50 \mathrm{mmol} / \mathrm{l}$ Tris ( $\mathrm{pH} 7.5$ ) containing $0.2 \mathrm{~mol} / 1 \mathrm{NaCl}$ (Tris buffered saline, TBS) for 10 min. The sections were incubated with methanol for $30 \mathrm{~min}$ to inhibit endogenous peroxidase, with $0.03 \% \mathrm{H}_{2} \mathrm{O}_{2}$ in 20 $\mathrm{mmol} / \mathrm{l}$ sodium phosphate $(\mathrm{pH} 7.5)$ containing $0.15 \mathrm{~mol} / \mathrm{l}$ $\mathrm{NaCl}$ (phosphate-buffered saline, PBS) for $30 \mathrm{~min}$, and with TBS containing $5 \%(\mathrm{w} / \mathrm{v})$ bovine serum albumin for $30 \mathrm{~min}$. These sections were then incubated for $48 \mathrm{~h}$ with polyclonal antibodies to a subunit of Gs (Dupont, Wilmington, USA) (13) at a final dilution of 1:50 in TBS; as a control, sections were incubated with nonimmune rabbit immunoglobulin G. After washing three times with PBS, the sections were incubated for $16 \mathrm{~h}$ with horseradish peroxidase-labeled goat antibodies to rabbit immunoglobulin $G$ (Amersham, Buckinghamshire, UK) at a final dilution of 1:20 in TBS. After washing three times with PBS, the sections were incubated with $50 \mathrm{mmol} / \mathrm{l}$ Tris $(\mathrm{pH} 7.5)$ containing $0.02 \%$ 3,3'-diaminobenzidine tetrahydrochloride (Dojindo, Tokyo, Japan) for $30 \mathrm{~min}$ at room temperature and then with the same solution containing $0.01 \% \mathrm{H}_{2} \mathrm{O}_{2}$ for $10 \mathrm{~min}$. The sections were washed twice with PBS for $10 \mathrm{~min}$, embedded in 50\% (v/w) glycerol in PBS, and examined by light microscopy.

An interactive build analysis system (Kontron, Munich, Germany) was used to generate 256-step gray images, and the wall thickness/lumen diameter ratio was measured. The gray scale levels of the images were displayed. Since it is difficult to measure all sections under exactly the same conditions, the gray scale index was calculated by subtracting the mean gray scale level of 10 background sites (each 5 pixels in size) from the mean gray scale level of 10 immunoreactive sites (each 5 pixels in size) in vascular smooth muscle (the center of the media). The fibrotic tissues around the small artery were regarded as the background sites. The mean gray scale levels of 5 sections in each rat were regarded as the gray scale index. This gray scale index was then regarded as the relative concentration level of the immunoreactive concentration.

\section{Functional Analysis}

SHR (aged 4 and 10 weeks; each group, $n=6$ ) and agematched WKY (each group, $n=6$ ) were anesthetized with phenobarbital $(0.1 \mathrm{mg} / \mathrm{g}$, intramuscularly). After the scrotum was opened, the right cremaster muscle was separated from the subdermal connective tissue and incised along the ventral surface, and the testicle was removed. The cremaster was then quickly excised, rinsed in cold saline, and placed in a temperature-controlled $\left(4^{\circ} \mathrm{C}\right)$ dissection chamber containing sterile physiological salt solution that consisted of (in mmol/l): $\mathrm{NaCl} 145, \mathrm{KCl} 4.7, \mathrm{CaCl}_{2} \cdot 2 \mathrm{H}_{2} \mathrm{O} 2.0, \mathrm{MgSO}_{4} \cdot 7 \mathrm{H}_{2} \mathrm{O}$ 1.2, glucose 5.0, pyruvate 2.0, MOPS [3-(N-morpholino) propanesulfonic acid] 3.0, EDTA 0.02, $\mathrm{NaH}_{2} \mathrm{PO}_{4}$ 1.2, $\mathrm{C}_{27} \mathrm{H}_{38} \mathrm{~N}_{2} \mathrm{O}_{4} \cdot \mathrm{HCl} 0.5(\mathrm{pH} 7.4)$ and $1 \%$ bovine serum albumin. Techniques used for the microcannulation of resistance vessels resembled those described previously (14-16). The cremaster muscle was pinned flat, and a 1- to $1.5-\mathrm{mm}$ length of the cremaster small artery (diameter $100 \mu \mathrm{m}$ ) in the center of the tissue that was free of side branches was identified with a dissection microscope (magnification: $\times 50-\times 125$ ). The vessel was separated from the surrounding tissue with ultrafine scissors and forceps (Fine Science Tools Inc., Foster City, USA) and was transferred to a water-jacketed tissue bath with attached micro pipette micromanipulators. The vessel was cannulated at both ends with a fluid-filled glass micropipette (60 $\mu \mathrm{m}$ outside diameter) and 11-0 ophthalmic sutures $(18 \mu \mathrm{m})$. The pipette and the vessel were filled with a modified Krebs solution that consisted of (in mmol/l): $\mathrm{NaCl}$ 118.5, $\mathrm{KCl} 4.7, \mathrm{CaCl}_{2} \cdot 2 \mathrm{H}_{2} \mathrm{O} \quad 2.55, \mathrm{MgSO}_{4} \cdot 7 \mathrm{H}_{2} \mathrm{O}$ 1.19, $\mathrm{KH}_{2} \mathrm{PO}_{4} 1.19, \mathrm{NaHCO}_{3} 19.9$ and dextrose 11.6. One pipette was connected to a Krebs reservoir whose height could be adjusted within 1-2 $\mathrm{s}$ to produce changes in intraluminal pressure that were measured with a pressure transducer in parallel with the pipette perfusion line. The second pipette 

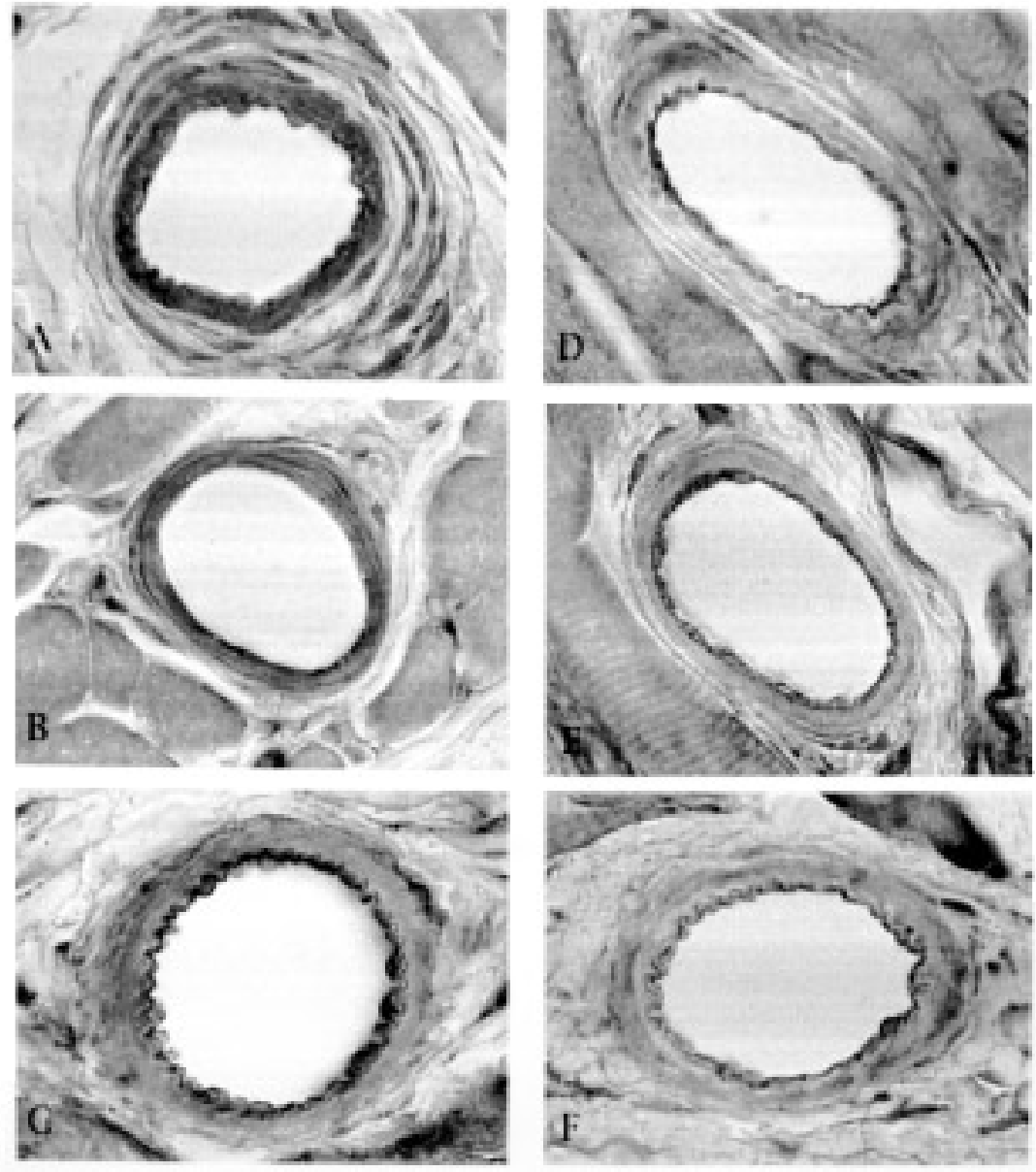

Fig. 1. Gs-like immunoreactivity (LIR) of the peripheral resistance arteries of WKY and SHR at 4 (WKY: A; SHR: D), 10 (WKY:B; SHR: E), and 20 (WKY: C; SHR: F) weeks of age. Gs-LIR was localized specifically in the vascular smooth muscle and was less abundant in SHR than in the age-matched WKY.

was closed to eliminate any flow-related vasoactive stimuli. The covered $5 \mathrm{ml}$ tissue bath was continuously exchanged (4 $\mathrm{ml} / \mathrm{min}$ ) without recirculation from a Krebs reservoir where $\mathrm{pH}$, temperature and gases were adjusted to maintain the tissue bath at $\mathrm{pH} 7.35-7.45, \mathrm{PaO}_{2}$ 65-75 $\mathrm{mmHg}$ and $\mathrm{Paco} 2$ $35-40 \mathrm{mmHg}$. Other drugs were applied to the tissue bath by means of syringe infusion pumps connected to the Krebs suffusion line, using drug infusion rates of $8-15 \mathrm{ml} / \mathrm{min}$. The vessel preparation was then transferred to the stage of an inverted microscope (Diaphot; Nikon, Tokyo, Japan). The vessel was imaged with $\mathrm{a} \times 20,0.5 \mathrm{NA}$ planapochromat (Nikon, Tokyo, Japan) and a CCD camera (C2400; Hamamatsu Photonix, Tokyo, Japan). The diameter of the lumen was measured with a digital image analysis system (Argus 10, Hamamatsu Photonix, Tokyo Japan) that was calibrated with a stage micrometer. To evaluate the viability and stability of the smooth muscle preparation, the temperature of the bath was gradually increased over $90 \mathrm{~min}$ to $34^{\circ} \mathrm{C}$ at an in vivo pressure of $40 \mathrm{mmHg}$. During this period of equilibrium, the vessel developed an intrinsic tone. Any vessels that failed to

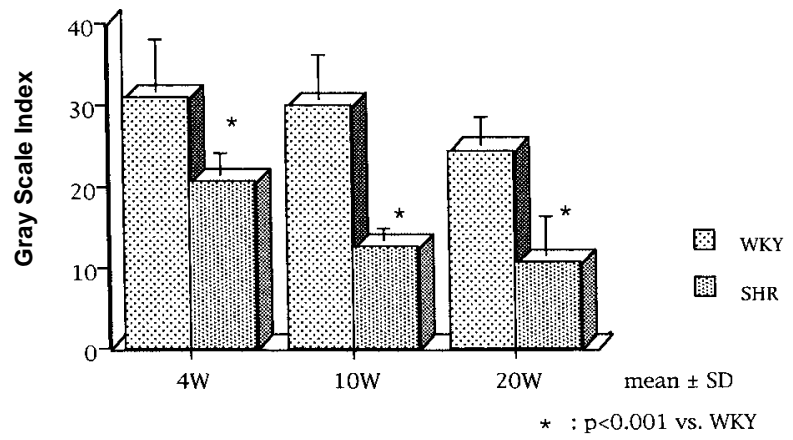

Fig. 2. The gray scale indexes of Gs-LIR in rats at 4, 10, and 20 weeks of age. The gray scale indexes of Gs-LIR in SHR at 4, 10, and 20 weeks of age were significantly $(\mathrm{p}<0.001)$ lower than the corresponding values for agematched WKY. Moreover, the gray scale indexes of Gs-LIR in SHR at 10 and 20 weeks of age were significantly $(\mathrm{p}<0.001)$ lower than the corresponding values for those in SHR at 4 weeks of age (each group, $\mathrm{n}=7$ ). 

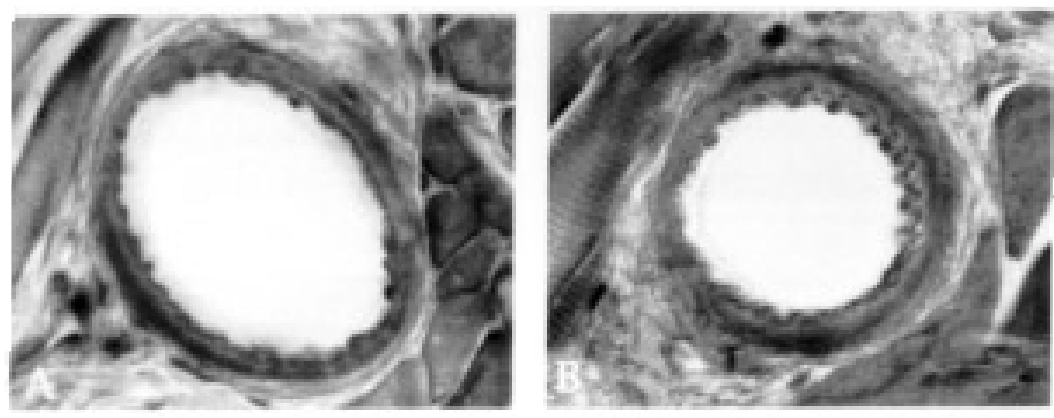

Fig. 3. The Gs-LIR values in the vascular smooth muscle of the cremaster arteries in RHR and WKY. There was no apparent difference in the pattern of Gs-LIR between RHR and WKY.

develop intrinsic tone and myogenic response were discarded (15). Prazosin $\left(10^{-7} \mathrm{~mol} / \mathrm{l}\right)$, acebutolol $\left(10^{-5} \mathrm{~mol} / \mathrm{l}\right)$, DLnormetanephrine $\left(10^{-5} \mathrm{~mol} / \mathrm{l}\right)$ and desipramine $\left(10^{-8} \mathrm{~mol} / \mathrm{l}\right)$ were added to the Krebs solution to block the $\alpha$ - and $\beta_{1}$-adrenoceptors, the nonneuronal and neuronal catecholamine uptake mechanisms, respectively (17). Indomethacin $\left(3 \times 10^{-6} \mathrm{~mol} / \mathrm{l}\right)$ was added to the Krebs solution to block prostaglandine, and $\mathrm{N}^{\omega}$-nitro-L-arginine methyl ester (300 $\mathrm{mmol} / \mathrm{l}$ ) was added to block endothelium-derived relaxing factor (EDRF).

We compared the concentration response curves produced by exposure to isoproterenol $\left(10^{-9}-10^{-5} \mathrm{~mol} / \mathrm{l}\right)$ between SHR and WKY. We also compared the concentration response curves produced by exposure to nitroprusside $\left(10^{-9}-10^{-5} \mathrm{~mol} / \mathrm{l}\right)$ between SHR and WKY. The vessels were then treated with cholera toxin (CTX; $5 \times 10^{-7} \mathrm{~mol} / \mathrm{l}$ for $1 \mathrm{~h}$ ) $(18)$, and we then compared the vessel diameter in small arteries between SHR and WKY before and after treatment of CTX. The changes of diameter by CTX showed the percentage of maximum dilation by nitroprusside $\left(10^{-5} \mathrm{~mol} / \mathrm{l}\right)$. (Preliminary results indicated that increasing the incubation time to $3 \mathrm{~h}$ did not alter the effect of CTX.)

Data are expressed as the means \pm SD and were analyzed by unpaired Student's $t$-test, as appropriate. Bonferoni procedures were used in making multiple comparisons among the concentration response data. Levels of $p<0.05$ were considered to indicate statistical significance.

\section{Results}

The systolic blood pressures of 4-, 10-, and 20-week-old SHR were $105 \pm 8,178 \pm 10$, and $198 \pm 8 \mathrm{mmHg}$, respectively, and those of age-matched WKY were $103 \pm 7,108 \pm 9$, and $115 \pm 8 \mathrm{mmHg}$, respectively. The wall thickness/lumen diameter ratio in the resistance artery (internal diameter, 70 to $80 \mu \mathrm{m})$ did not differ significantly between SHR and WKY at 4 or 10 weeks of age $(4 \mathrm{~W} \cdot \mathrm{SHR}$ : $0.12 \pm 0.02$; $4 \mathrm{~W} \cdot \mathrm{WKY}: 0.12 \pm 0.02 ; 10 \mathrm{~W} \cdot \mathrm{SHR}: 0.11 \pm 0.03 ; 10 \mathrm{~W} \cdot$ WKY: 0.12 \pm 0.02). However, the ratio in SHR (0.22 \pm 0.05$)$ at 20 weeks of age was significantly $(p<0.001)$ greater than that in age-matched WKY $(0.17 \pm 0.02)$ or in SHR at 4 or 10 weeks of age.

Gs protein-like immunoreactivity (LIR) of the peripheral resistance arteries of WKY and SHR at 4, 10, and 20 weeks of age is shown in Fig. 1. Gs-LIR was localized specifically in the vascular smooth muscle and was less abundant in SHR than in the age-matched WKY.

The gray scale indexes of Gs-LIR in SHR at 4, 10, and 20 weeks of age were significantly $(p<0.001)$ lower than the corresponding values for age-matched WKY (Fig. 2). Moreover, the gray scale indexes of Gs-LIR in SHR at 10, and 20 weeks of age were significantly $(p<0.001)$ lower than the corresponding values for SHR at 4 weeks of age.

The systolic blood pressure, as measured by the tail cuff method, of RHR 3 weeks after surgery was $184 \pm 14 \mathrm{mmHg}$ as compared to $108 \pm 10 \mathrm{mmHg}$ for WKY of the same age. The wall thickness/lumen diameter ratio in the resistance artery did not differ significantly between RHR $(0.13 \pm 0.02)$ and WKY $(0.12 \pm 0.03)$. There was no apparent difference in the pattern of Gs-LIR in the cremaster artery between RHR and WKY (Fig. 3). The gray scale indexes of Gs-LIR in the vascular smooth muscle of the cremaster artery did not differ

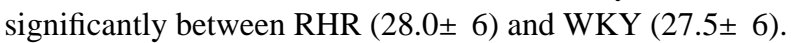

\section{Functional Analysis}

Figure 4 shows that the isoproterenol concentration-dilation response curves of SHR at both 4 and 10 weeks of age were significantly less than those of age-matched WKY.

The percentages of dilation by CTX in SHR (4W, 58\%; $10 \mathrm{~W}, 55 \%)$ in both age groups were less than that of agematched WKY (4W, 71\%; 10W, 68\%) (Fig. 5).

Figure 6 shows that the nitroprusside concentration-dilation response curves of SHR at both 4 and 10 weeks of age were not different from those of age-matched WKY. 


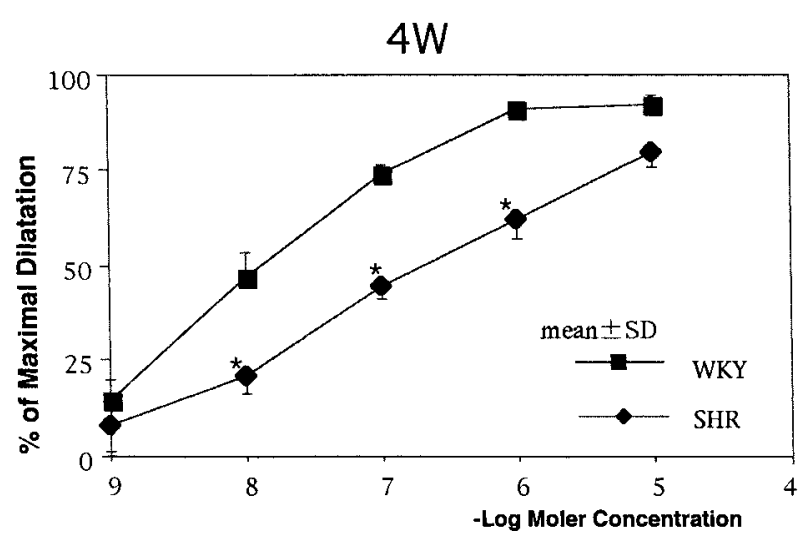

: $p<0.05$ vs. WKY

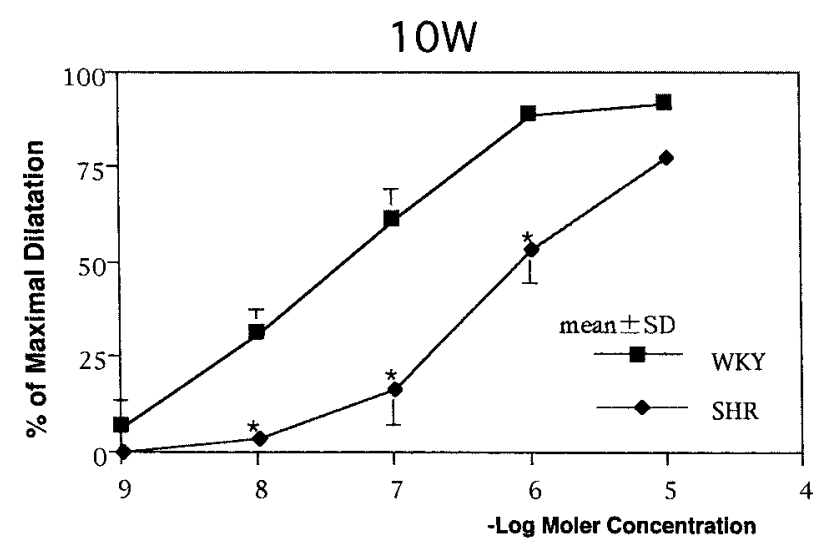

: $p<0.05$ vs. WKY

Fig. 4. The isoproterenol concentration-dilation response curves. The isoproterenol concentration-dilation response curves of SHR at both 4 and 10 weeks of age were significantly lower than of age-matched WKY (each group, $\mathrm{n}=6)$.
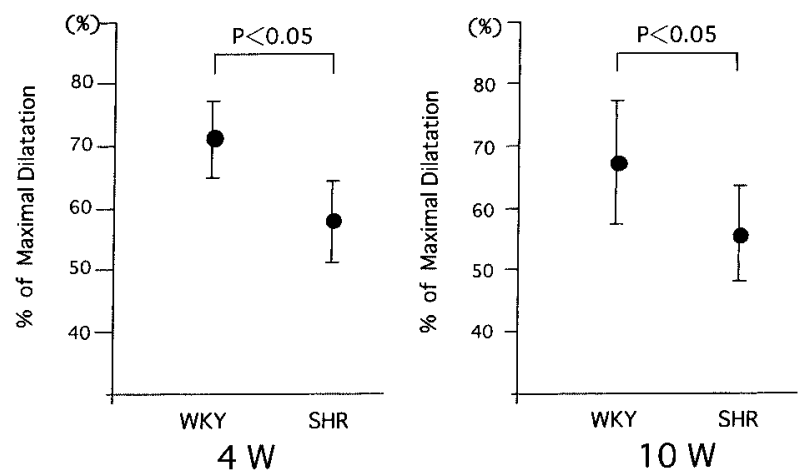

Fig. 5. The dilatory response by CTX in SHR (4 and 10 weeks of age) and age-matched WKY. The percentages of dilation by CTX in SHR in both age groups were less than those of age-matched WKY (each group, $\mathrm{n}=7$ ).

\section{Discussion}

Several pharmacological and biochemical abnormalities
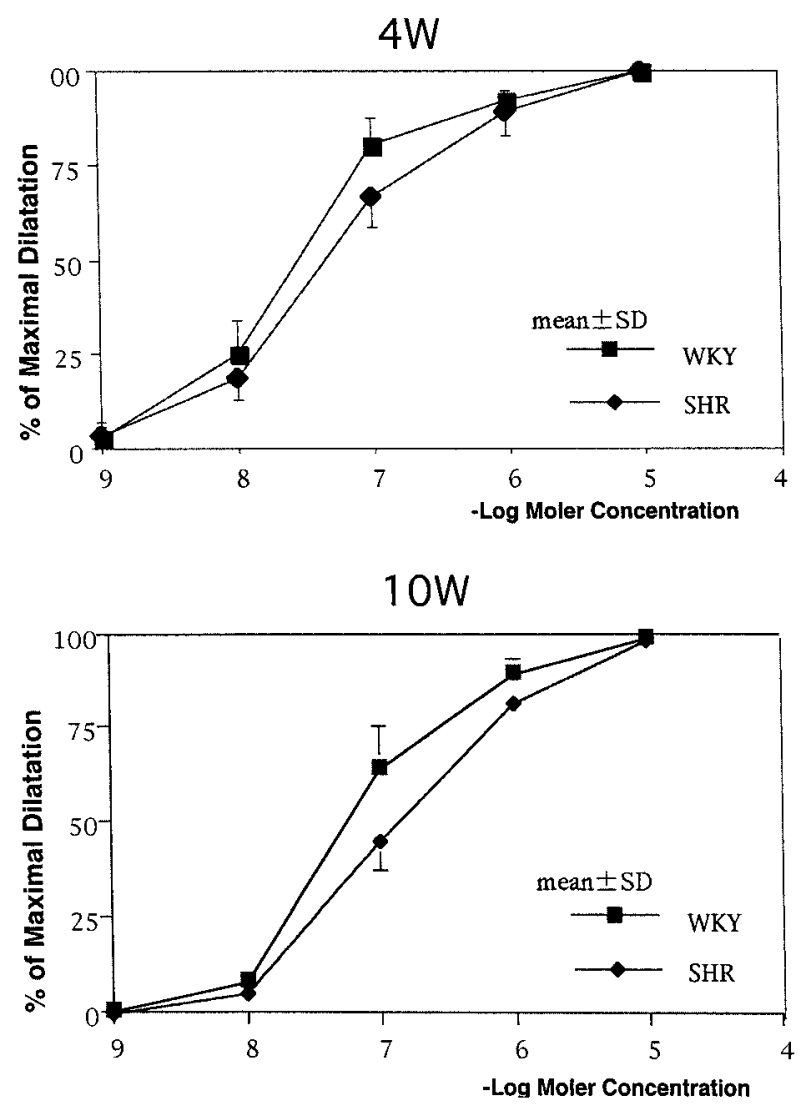

Fig. 6. The nitroprusside concentration-dilation response curves. The nitroprusside concentration-dilation response curves of SHR at both 4 and 10 weeks of age were not different from those of age-matched WKY (each group, $\mathrm{n}=7$ ).

have been reported in the Gs protein-linked signal transduction in animal models $(6-8)$ and patients with hypertension (19-21). However, these studies have implicated the role of $\mathrm{G}$ proteins in conduit vessels. Moreover, there are conflicting reports of changes in Gs protein in the smooth muscle of aorta and small arteries of hypertensive rats $(6-11,22,23)$. The concentration of Gs protein has not previously been examined in the peripheral resistance small arteries that regulate blood pressure and may play an important role in the maintenance of the hypertensive state. There has not been any study using Western blotting of Gs protein in the peripheral small arteries, because the low level of such protein in the small arteries makes it difficult to study by this method.

We examined the distribution of Gs protein in a peripheral resistance artery by immunohistochemical methods and semiquantitatively evaluated the abundance of Gs protein by image analysis. Our data showed a reduction in immunoreactive Gs protein in the peripheral small arterial smooth muscle in SHR before onset of hypertension. The decrease in the amount of Gs protein may be due to 1) the decrease of the production of Gs protein, 2) the augmentation of dissimilation of Gs protein, or 3) the abnormality of Gs protein genes. 
Since the amount of Gs protein did not decrease in the arteries of the secondary hypertensive rats, the reduced amounts of Gs protein in the arteries of SHR are likely attributable to genetic factors. Further studies are necessary to elucidate this point.

The correlation between the amount and function of Gs protein is elusive, because the percentage of total Gs protein that attributes to the function of Gs protein is not known. In our study, the immunoreactive Gs protein in the artery in SHR was reduced. Moreover, the function of Gs protein of SHR was reduced, because the vasodilator response to CTX was significantly lower in SHR than in WKY. Our data suggest a possibility that reduced function of Gs protein may be due to decreased amount of Gs protein. Since there were no differences in the amount of Gs protein in RHR (secondary hypertensive rats) compared with WKY, we did not study the Gs protein function in RHR.

We did not investigate the number of $\beta_{2}$-adrenoceptors, because the amount of protein in the resistance small arteries was too low for a receptor binding assay. However, the reduced amount and function of Gs protein may attenuate the dilator response by $\beta_{2}$-adrenoceptor stimulation. Our data showed that the vasodilator responsiveness of $\beta_{2}$-adrenoceptor (stimulation of isoproterenol in the presence of $\beta_{1}$ adrenoceptor blockade) was reduced. Our findings are consistent with the data from previous studies: Nobel et al. (22) showed that the resistance of peripheral resistance vessels in SHR aged 10 to 12 weeks was increased and the vascular dilation response was reduced. Asano et al. showed that in SHR aged 13 weeks, the reduced relaxation by $\beta$-adrenoceptor agonists of femoral arteries was due to a functional loss of Gs protein $(10,11)$. However, our study does not exclude the possibility that the functional decrease in Gs protein might be due to the decrease of the $\beta$ receptor capacity.

Our results suggest that reduction of dilator responsiveness in the small arteries is due to impairment of the $\beta$ adrenoceptor-Gs protein system before the onset of hypertension in SHR. This impairment of dilator responsiveness may increase peripheral vascular resistance and thereby contribute to the development and maintenance of hypertension in SHR. However, if a decrease in the function of Gs protein is involved in the development of hypertension, then the appearance of such a decrease in advance of the onset of hypertension would appear to constitute a contradiction. We have previously reported a decrease in the amount and function of Gi protein in the resistance small arteries in SHR before the onset of hypertension. Since the contraction of resistance arteries is mediated via $\alpha_{2}$-adrenoceptors coupled to Gi protein, a decrease in the amount of Gi protein may suppress the contractile response. This attenuated contraction in the resistance small arteries via Gi protein may compensate for the decreased dilatory response via the $\beta$-adrenoceptor-Gs protein system. However, this compensation mechanism may collapse with the advancement of age, or a mechanism not involving Gs protein may be involved in the development of hypertension. When hypertension develops due to a mechanism not involving Gs protein, the decreased dilator response may work as an accelerative factor, leading to a greater rise in blood pressure and a maintenance of the higher level. Further studies are necessary to elucidate this point.

Although vascular endothelial cells are important regulators of vascular resistance (23), it is difficult to study G protein expression in these cells with the approach adopted here. Further studies will also be needed to elucidate this point.

In conclusion, these early changes in the concentration and function of Gs protein in the smooth muscle of a peripheral resistance vessel in SHR may reflect impaired receptormediated signal transduction and may be one of the possible mechanisms responsible for the pathogenesis of hypertension.

\section{References}

1. Gilman AG: G proteins: transducers of receptor generated signals. Annu Rev Biochem 1987; 56: 615-649.

2. Schulze W, Kosler A, Hinsch K, et al: Immunnocytochemical localization of G-proteins ( $\alpha$ subunits) in rat heart tissue. Eur Heart J 1991; 12 (Suppl F): 132-134.

3. Hall K, Harding J, Hosick H: Isolation and characterization of clonal vascular smooth muscle cell line from spontaneously hypertensive and normotensive rat aortas. In Vitro Cell Dev Biol 1991; 27A: 791-798.

4. Masutani M, Ohyanagi M, Shibuya J, Ishigami Y, Iwasaki $\mathrm{T}$ : A decrease in the amount and function of inhibitory GTP-binding protein in the resistance small artery from spontaneously hypertensive rats. Jpn J Pharmacol 1999; 79: $185-193$

5. Clark CJ, Milligan G, Connell JM: Guanine nucleotide regulatory protein alterations in young Milan hypertensive strain rats. Biochim Biophys Acta 1994; 1225: 149-157.

6. Thibault C, Anand-Srivastava M: Altered expression of Gprotein mRNA in spontaneously hypertensive rats. FEBS Lett 1992; 313: 160-164.

7. Clark C, Milligan G, McLellan A, Connell M: Guanine nucleotide regulatory protein level and function in spontaneously hypertensive rat vascular smooth-muscle cells. Biochim Biophys Acta 1992; 1136: 290-296.

8. Clark C, Milligan G, McLellan A, Connell M: Guanine nucleotide regulatory proteins in the spontaneously hypertensive rat. Hypertension 1993; 21: 204-209.

9. Stekiel W, Contney S, Rusch N: Altered $\beta$-receptor control of in situ membrane potential in hypertensive rats. Hypertension 1993; 21: 1005-1009.

10. Asano M, Masuzawa K, Matsuda T, Asano T: Reduced function of the stimulatory GTP-binding protein in $\beta$ adrenoceptor-adenylate cyclase system of femoral arteries isolated from spontaneously hypertensive rats. J Pharmacol Exp Ther 1988; 246: 709-718.

11. Asano M, Masuzawa K, Matsuda T: Role of stimulatory GTP-binding protein (Gs) in reduced $\beta$-adrenoceptor coupling in the femoral artery of spontaneously hypertensive rats. Br J Pharmacol 1988; 95: 241-251.

12. Prewitt R, Chen I, Dowell R: Microvascular alterations in 
the one-kidney, one-clip renal hypertensive rat. Am J Physiol 1984; 246: H728-732.

13. Anand-Srivastava M: Enhanced expression of inhibitory guanine nucleotide regulatory protein in spontaneously hypertensive rats: relationship to adenylate cyclase inhibition. Biochem J 1992; 288: 79-85.

14. Duling BR, Gore RW, Dacey RG Jr, Damon DN: Methods for isolation, canulation, and in vitro study of signal microvessels. Am J Physiol 1981; 241: H108-H116.

15. Shibuya J, Ohyanagi M, Iwasaki T: Enhanced myogenic response in resistance small arteries from spontaneously hypertensive rats: relationship to the voltage-dependent calcium channel. Am J Hypertens 1998; 11: 767-773.

16. Ikeoka K, Nishigaki K, Ohyanagi M, Faber JE: In vitro analysis of alpha-adrenoceptor interactions with myogenic response in resistance vessels. J Vasc Res 1992; 29: 313-321.

17. Febar JE, Meininger GA: Selective interaction of alphaadrenoceptors with myogenic regulation of microvascular smooth muscle. Am J Physiol 1990; 257: H1126-H1131.

18. Flavahan NA, Shimokawa H, Vanhoutte PM: Pertussis tox- in inhibits endothelium-dependent relaxation to certain agonists in porcine coronary arteries. J Physiol (Lond) 1989; 408: 549-560.

19. Yoshikawa H, Fukuda K, Wanaka Y, et al: Deficient activity of stimulatory nucleotide-binding regulatory protein in lymphocytes from patients with essential hypertension. Am J Hypertens 1994; 7: 713-716.

20. Feldman RD, Tan CM, Chorazyczewski J: G protein alterations in hypertension and aging. Hypertension 1995; 26: 725-732.

21. Feldman RD, Lawton WJ, McArdle WL: Low sodium diet corrects the defect in lymphocyte beta-adrenergic responsiveness in hypertensive subjects. J Clin Invest 1987; 79: 290-294.

22. Nobel J, Smith T, Hutchins P, Struyker-Boudier A: Microvascular alterations in adult conscious spontaneously hypertensive rats. Hypertension 1990; 15: 415-419.

23. Ohno M, Gibbons GH, Dzau VJ, Cooke JP: Shear stress elevates endothelial cGMP role of a potassium channel and G protein coupling. Circulation 1993; 88: 193-197. 